\title{
Application of Anticorrosive Techniques Compatible with the Environment to Engineering Education
}

\author{
Fernando B. Mainier*, Fabiana R. Leta, Flávio F. Feliciano \\ Universidade Federal Fluminense, Niterói, RJ, Brazil
}

\begin{abstract}
The media has shown the major problems caused by pipeline leaks; however, the contamination caused by storage tanks of fuel and chemicals is not always shown to the general public, especially when the holes are located on the bottom of the tank. Most of the time the groundwater contamination goes unnoticed and will only be confirmed much later when soil decontamination is impractical due to the high costs involved. Corrosion problems occurring in gas station tanks are one of the examples of the everyday discipline concerning corrosion belonging to the courses Chemical Engineering and Mechanical Engineering of the Universidade Federal Fluminense (Fluminense Federal University), which aims to encompass anticorrosive techniques compatible with the environment through a program based on basic knowledge of corrosion and experiments. This work is an attempt to link and integrate the knowledge of corrosion and anticorrosive techniques for the benefit of the environment in order to develop a scientific-technical approach that includes ideas generated and the experiences gained in the teaching and researching of these techniques.
\end{abstract}

Keywords Corrosion, Cathodic protection, Contamination, Environment

\section{Introduction}

Carbon steel has been the most frequently used material in most segments of basic production of the assets of society. In recent decades, there has been considerable progress in both the manufacture of new ferrous alloys and the development of new materials. But, because of the low cost and the extent of the use of carbon steel, field exposure decay is also expected to occur broadly.

According to Revie [1], corrosion processes have led to a number of everyday problems in construction, explosions of boilers, water mains disruptions, and oil spills caused by holes in tanks and pipelines. In petroleum refining and petrochemical facilities, about $50 \%$ of failures are attributed to materials corrosion.

According to Roberge [2] and Baeckmann et al. [3], parks of fuel tanks and chemicals in general are subject to internal and external corrosion due to the products and the prevailing environmental conditions, respectively. The risk of pollution caused by leaks depends on the local hydrogeological conditions.

Accidents involving environmental pollution load in the basement often involve petroleum or hazardous chemicals or both. That charge can also be caused by transport, leakage due to operational failures, or corrosion of buried pipes and

* Corresponding author:

fmainier@uol.com.br (Fernando B. Mainier)

Published online at http://journal.sapub.org/ajee

Copyright (C) 2014 Scientific \& Academic Publishing. All Rights Reserved tanks. The numerous cases of leaks in gas stations from underground fuel storage tanks have caused irreparable damage to the environment and compromise the safety and quality of life of people living in the vicinity of these locations [4].

Generally, fuel leaks occurring at gas stations into the environment are caused by internal or external corrosion of pipes and underground tanks. Brazilian estimates show that around $40 \%$ of these leaks are caused by corrosion and the remainder by mounting failures, leaking joints, operational failures, and so on. The damage caused by corrosion damage, from the economic point of view, leads to extremely high direct and indirect costs, resulting in considerable waste of investment, not to mention accidents and loss of life, caused by contamination, pollution, and lack of safety equipment [3-5].

In assessing costs, sometimes the value of a new material to replace the old one is about 20 to 50 times more expensive events that end up determining the option to use a chemical additive to delay or inhibit the corrosion process.

This leads to results which are often more disastrous, in view of the toxicity of these products, eventually leading to their dumping or leaking into the environment with much greater aggression.

Due to the astronomical figures for waste - about $3.5 \%$ of Gross National Product - the major industries of the first world are investing in research in order to rethink projects and processes in a combinatorial search for solutions that are more effective and less costly. 
Even with the technological advances in the development of new materials, new chemicals, new processes, or adaptations of traditional processes persist, it is not that trigger, directly or indirectly, other corrosion problems, requiring further studies, as is the case for special alloys or high strength composite materials.

These events ultimately mean that corrosion is a continuous challenge to mankind, because the more science evolves, creating and applying technology and advances, the more space and ways are found to do this.

The discipline of Corrosion and Corrosion Protection offered by engineering courses at the Fluminense Federal University has sought to associate and integrate the knowledge of corrosion and protective techniques for the benefit of the environment in order to develop a scientific-technical approach that will include ideas generated and experiences in the teaching and research of these techniques.

To facilitate this process of teaching and learning (Figure 1), leaking tanks at gasoline stations were taken as the central theme, in view of the interaction with ordinary people, the wide media coverage in relation to leaks and explosion risks, and finally the fact that in Brazil the number of these underground tanks with capacities ranging from 5,000 to $10,000 \mathrm{~L}$ is greater than 120,000 .

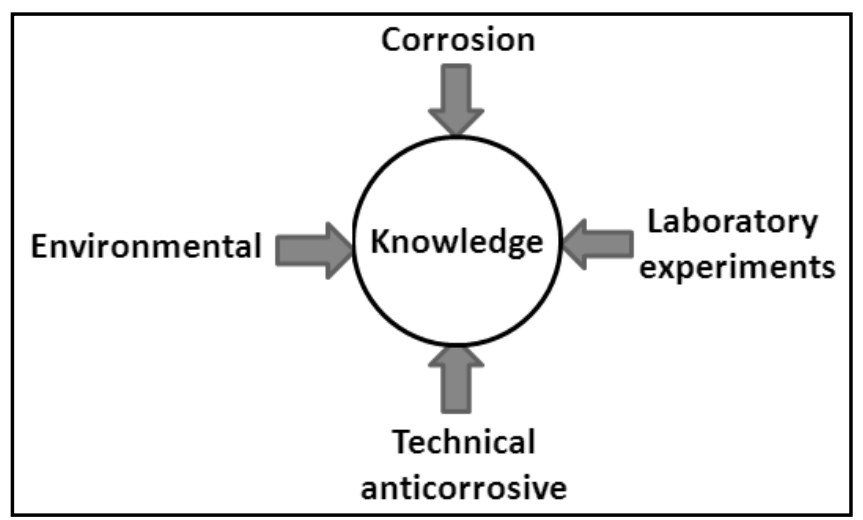

Figure 1. Scheme of teaching and learning

\section{Environmental Contamination Caused by Leaks from Gas Station}

The process of acquiring knowledge on the principles of corrosion and corrosion protection as well as its practical suitability in the field of engineering equipment has been a challenge in our country, because besides the high costs involved; in some cases there may be contamination of products, environmental pollution, and security compromises, causing accidents and even loss of life.

Considering the high number of gasoline and diesel oil tanks buried in soil together with the tropical climate and marine environment, the problem is becoming serious because, considering that some tanks are probably more than 20 years old, it is expected that the metal structure may be compromised by corrosion.
Figure 2 below shows some tanks removed from gas stations showing severe corrosion.

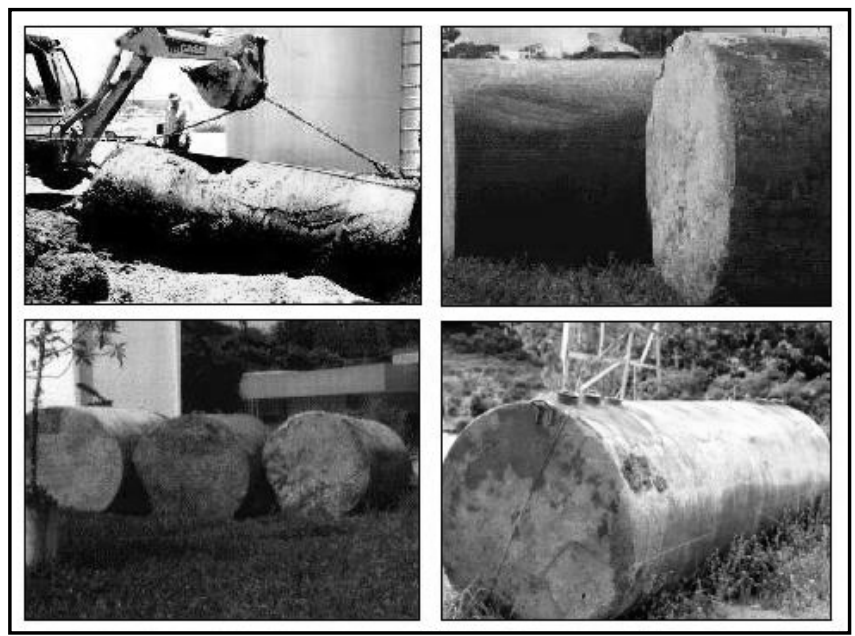

Figure 2. Aspects of general corrosion in tanks of gas stations in Brazil

As a reference, Figure 3 shows some journalistic news clippings regarding cases of leaks at gas stations where insecurity, contamination, and panic about possible explosions were reported, causing great inconveniences to daily life in cities.

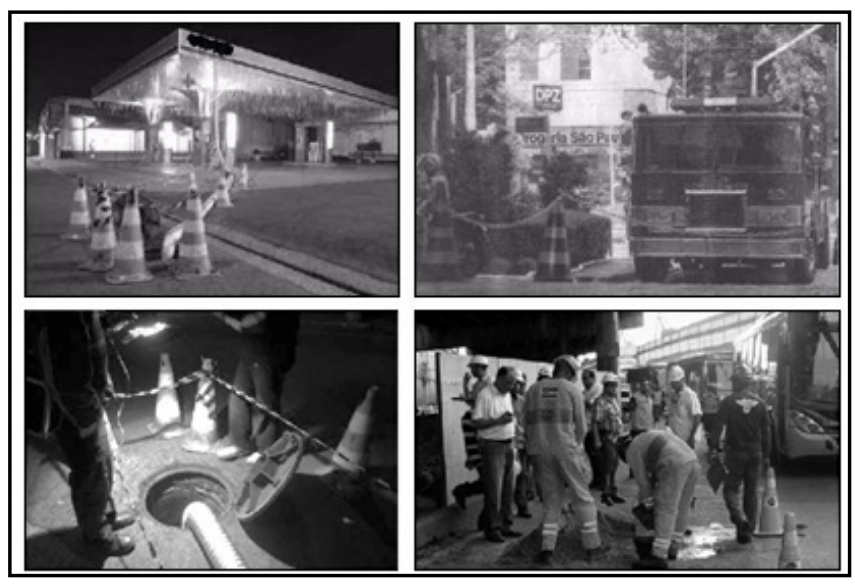

Figure 3. Aspects of leaks occurring at gas stations in Brazil

\section{Mechanism of Corrosion}

Carbon steel structures buried in soil in direct or indirect contact with freshwater or saltwater which is aggressive and either aerated or not aerated may be exposed to electrochemical corrosion or electrolytic corrosion.

Electrochemical corrosion is a spontaneous process that is likely to occur when the metal or alloy is in contact with an electrolyte, which hosts both the anodic and cathodic reactions. The transfer of electrons from anodic to cathodic region is done by a metallic conductor, and the diffusion of anions and cations in solution closes the electrical circuit.

The intensity of the etching process is evaluated by the number of loads ions are discharged at the cathode or else the number of electrons that migrate from the anode to the 
cathode. The anodic and cathodic reactions involved in one example of this corrosion process are shown in Figure 4.

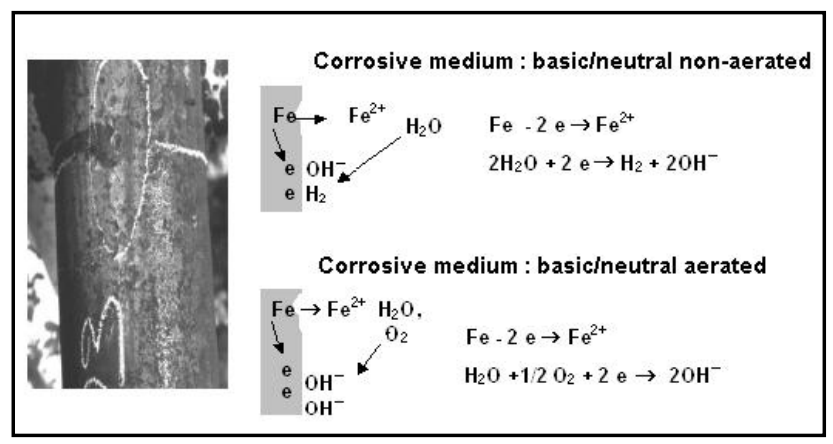

Figure 4. Mechanism of electrochemical corrosion

Electrolytic corrosion is characterized by an electrochemical process that occurs with external application of an electric current. This means that the process is not spontaneous corrosion. It is caused by leakage currents, also called stray currents, stray-current electrolysis, parasite currents, or strange currents. This phenomenon often occurs in oil pipelines, drinking water mains, telephone cables, buried tanks at gas stations, and so on. Generally, these currents are due to deficiencies in insulation or grounding out of specifications $[3,5]$.

Typically, localized holes occur in isolated facilities where the stray current escapes from electric networks or electric railways into the ground, as shown in the proposed mechanism in Figure 5, while the picture shown in Figure 6 illustrates major external wells and localized penetration of the walls of the tubes. It is observed that corrosion proceeds from the outside of the steel.

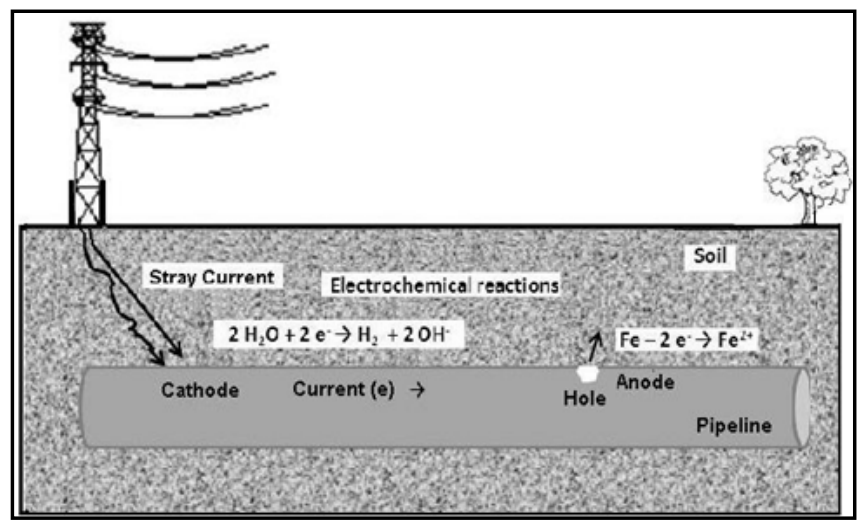

Figure 5. Mechanism of electrolytic corrosion

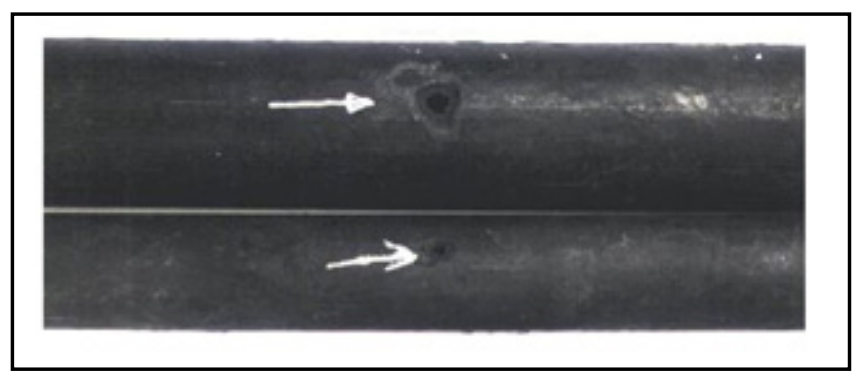

Figure 6. Located examples of electrolytic corrosion

\section{Corrosion Protection}

Cathodic protection is a technique based on the principles of electrochemistry that transforms the metallic structure by protecting it in an artificial cell, thus preventing deterioration of the structure. It is thanks to the cathodic protection of thousands of miles of buried pipelines for the transport of water, oil, gas, and chemicals, as well as major port facilities and offshore oil production, that buried tanks operate safely, protected from corrosion $[3,5]$.

Cathodic protection of steel structures is based on injection of electrical current through two techniques: protection by galvanic anodes (spontaneous) and impressed current protection (non-spontaneous).

Systems of galvanic or sacrificial anodes for current cathodic protection are provided by the potential difference that exists between the galvanic anode (aluminum, magnesium, or zinc) and the metal structure of carbon steel. In cathodic protection of a metallic structure, the flow of electric current is provided by the potential difference between the metal surface to be protected and the anode, which has a more negative potential, according to the following electrochemical reactions:

Anodic: $\mathrm{Zn}-2 \mathrm{e}^{-} \rightarrow \mathrm{Zn}^{2+}$

Cathodic: $2 \mathrm{H}_{2} \mathrm{O}+2 \mathrm{e}^{-} \rightarrow \mathrm{H}_{2}+2 \mathrm{OH}^{-}$

Figure 7 represents the system of protection with galvanic anodes (zinc) for the buried tanks of a gas station.

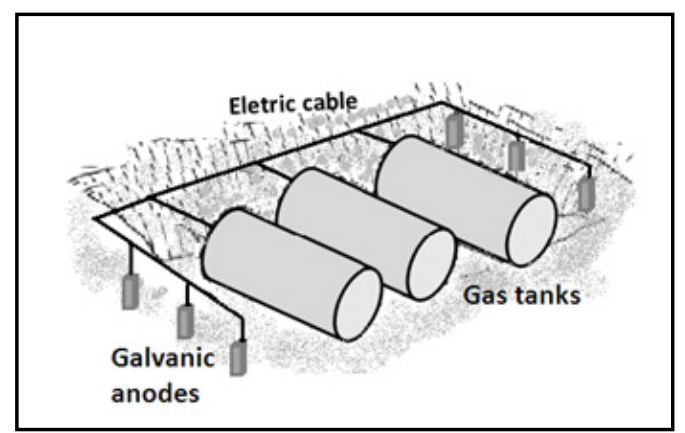

Figure 7. Protection system with galvanic anodes (zinc) for buried tanks at a gas station

The anodes used in cathodic protection are made of aluminum, magnesium, and zinc. Their selection in the design of the protection system will depend on several factors, the most important being the cost and resistivity or conductivity of the medium. The anodes have limitations: zinc can be used on land and in seawater, magnesium in freshwater, and aluminum in seawater.

Galvanic anode systems have some limitations and drawbacks; for example, they cannot be used where there are stray currents or interference, they do not allow adjustment of the injected current, and the anodes must be replenished after consumption.

In impressed current cathodic protection, buried metal structures receive the protection current from an external source or current rectifier installed on the surface and using a set disperser current in the electrolyte consisting of a bed of 
inert anode. The inert or nearly inert anodes can be made of graphite, iron-silicon alloys, platinum clad titanium, and 2\% silver-lead. The source of electrical current represented by the rectifier converts AC power into DC current and injects this into the soil by means of inert anodes, whose selection depends on several factors such as the cost, useful life, conductivity, and resistivity of the corrosive medium $[3,5$, $6]$.

The corrosion of buried pipes and tanks in gas service stations can be eliminated by proper application of cathodic protection (Figure 8). Cathodic protection acts as a complement to the faults and pitting of outer tanks and also protects galvanized pipes efficiently.

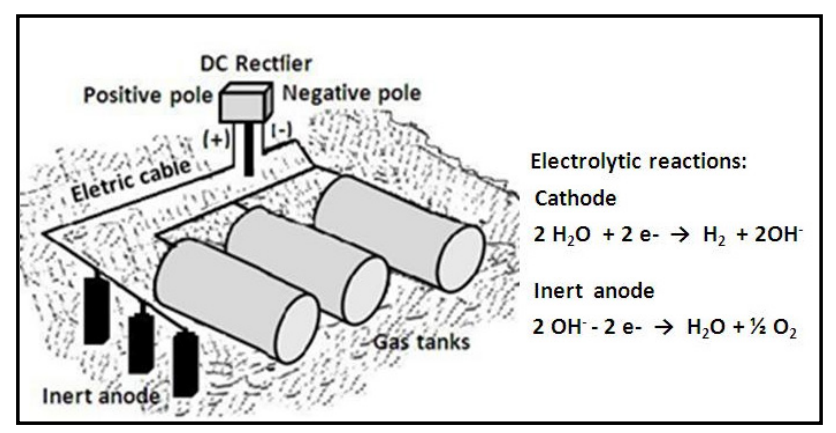

Figure 8. Impressed current cathodic protection of buried tanks at a gas station

The coatings used to coat the external cells of tanks at an economic scale cannot eliminate corrosion. They have pores and flaws, which can absorb moisture and stale over time, leaving spots or areas exposed to the soil. The current cathodic protection penetrates the exposed areas precisely, totally eliminating corrosion in any season and at any point of the tank where these flaws and pores appear. In such cases conventional coatings alone cannot ensure the protection of buried tanks but need to be supplemented by cathodic protection

After installing the cathodic protection system, it is necessary to verify that the tanks are protected against corrosion. This check should be done by measuring the potential of the tanks in the ground. Since the tanks are kept within minimum levels of potential, external corrosion will be eliminated, whatever the state of the coating used.

Accordingly, this technique minimizes the possibility of leakage and environmental contamination. Measurements of the potentials of tanks or floors of a filling station must be done with the aid of a voltmeter having high internal resistance and a reference electrode of $\mathrm{Cu} / \mathrm{CuSO}_{4}$ (copper/copper sulfate) so that the system of cathodic protection of the potential tank or soil is equal to or more negative than $-0.85 \mathrm{~V}$, measured between the tank and the reference electrode $\mathrm{Cu} / \mathrm{CuSO}_{4}[5,7,8]$.

\section{Laboratory Experiments}

The experiments presented below aim to:
- facilitate and broaden the understanding of the corrosion process and techniques of cathodic protection;

- arouse in the students the need to develop and clarify the physic-chemical mechanisms involved in each process;

- stimulate the relentless pursuit of technological innovation through special projects, and if necessary break the traditional course of the experiments;

- form technical and critical technical-environmental consciousness in students

\subsection{Description of Experiment 1: Corrosion of a Steel Plate without Uncoated Carbon Steel Compared to a Steel with Two Coats of Epoxy Paint Risk Penetrating}

Two carbon steel plates $(20 \mathrm{~cm} \times 10 \mathrm{~cm})$, one coated with two coats of epoxy paint with a total thickness of 250 $\mu \mathrm{m}$, are fixed in the holder and immersed in a transparent acrylic container with a capacity of $50 \mathrm{~L}$ holding a solution containing $3.5 \%$ (by weight) sodium chloride, representing seawater, as shown in Figure 9. The plates should be immersed for 15 days to evaluate the performance of the corrosion process.

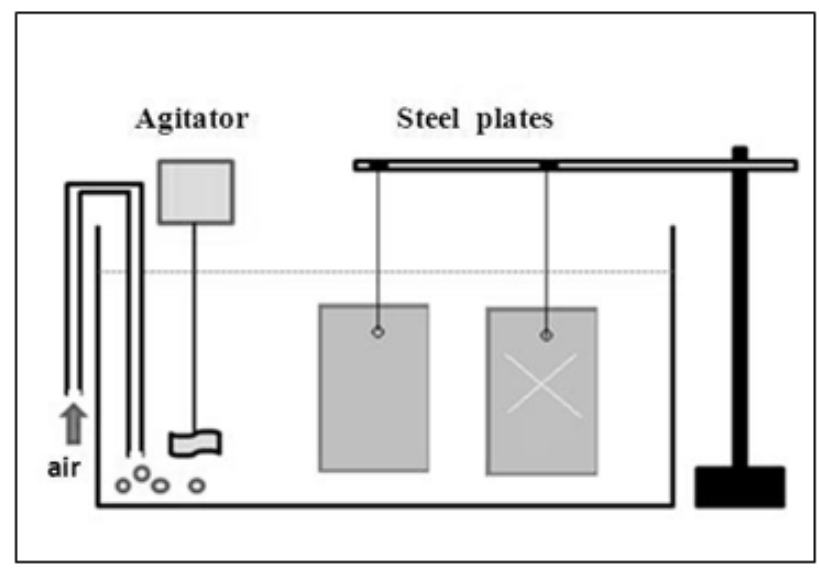

Figure 9. Assay steel plates immersed in seawater

Figure 10A illustrates the progress of the corrosion process in the laboratory experiment on steel plates with and without epoxy coating. The progress of the corrosion process is evidenced in steel plates photographed after three days of immersion in salt water, as shown in Figure 10B. Note that the steel sheet is coated with epoxy which lines the corrosion area.

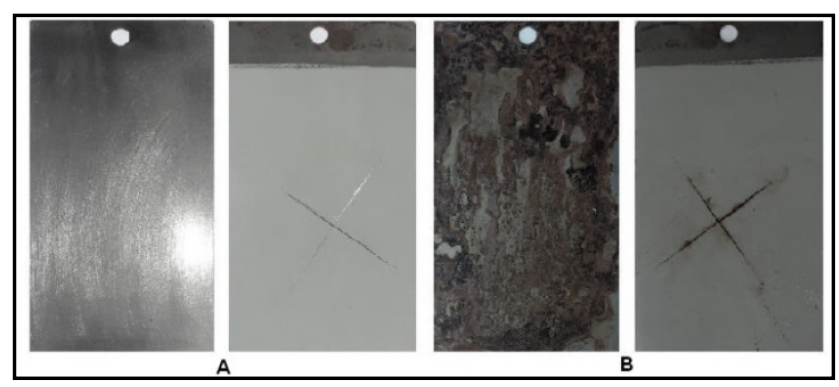

Figure 10. Development of the corrosion process (three days) 


\subsection{Description of Experiment 2: Cathodic Protection by Galvanic Anodes}

Two carbon steel plates $(20 \mathrm{~cm} \times 10 \mathrm{~cm})$ are fixed in the holder and immersed in a transparent acrylic container with a capacity of $80 \mathrm{~L}$ of solution containing $3.5 \%$ (by weight) sodium chloride, representing seawater, as shown in Figure 11. Each plate is connected to a galvanic anode (zinc and aluminum). Potential measurements are made twice daily to evaluate the cathodic protection. An agitator and an air bubbler are added to the system in order to create oxygenation and a corrosive environment.

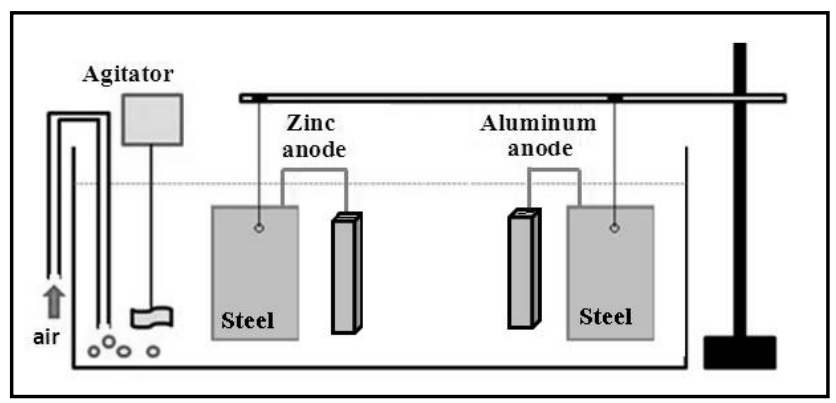

Figure 11. Assay of cathodic protection with galvanic anodes

\subsection{Description of Experiment 3: Impressed Current Cathodic Protection}

In this assay, cathodic protection in two corrosive media was investigated. A solution of $3.5 \%$ (by weight) $\mathrm{NaCl}$ represents seawater and a mixture of colorless gelatin with addition of sodium chloride represents a corrosive soil. The container for the seawater has a capacity of $20 \mathrm{~L}$, while the capacity of the container for the "gelatinous soil" is $3 \mathrm{~L}$. The assay for evaluation of impressed current cathodic protection essentially consists in placing the carbon steel plate in saltwater solution connected to the negative pole (-) of the DC rectifier while the graphite anode is connected to the positive pole $(+)$, as shown in Figure 12.

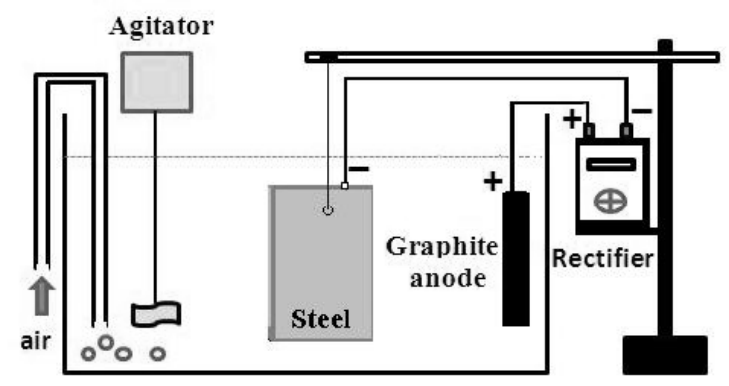

Figure 12. Assay for the evaluation of impressed current cathodic protection in salt water

The "gelatinous soil" is prepared by adding five envelopes of colorless and tasteless food gelatin (each envelope weighs about 12 to 15 grams) into a beaker containing $1500 \mathrm{~mL}$ of boiling water with constant stirring, and then adding $5 \mathrm{~g}$ $\mathrm{NaCl}$ and $1 \mathrm{~mL}$ of quaternary ammonium salt (biocide used in the pool). While continuing the constant stirring, the solution is transferred to the still warm acrylic container with a capacity of $3 \mathrm{~L}$. Then cold water is added and the solution is left to stand for 15 minutes. After this time the cathodic protection scheme comprising a carbon steel plate connected to the negative pole of the rectifier and the DC positive pole to the graphite anode is assembled, as shown in the diagrams of Figure 13.

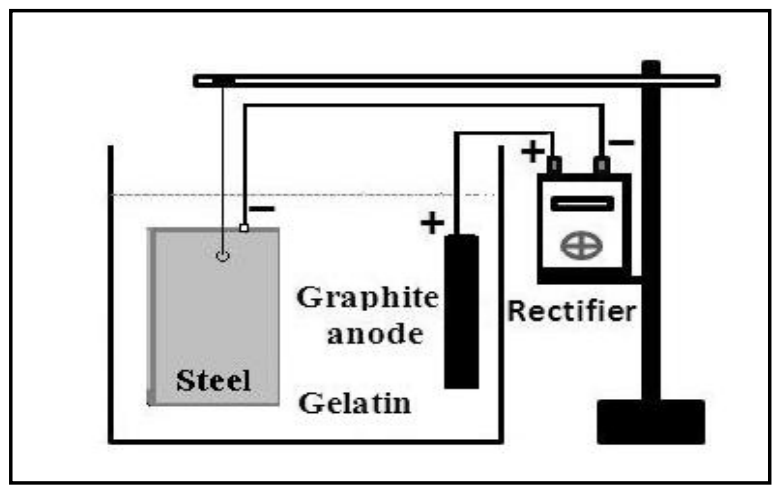

Figure 13. Assay for the evaluation of impressed current cathodic protection in "gelatinous soil"

\subsection{Considerations}

The experiments of cathodic protection (galvanic anodes and inert anodes direct current) presented in this paper show and reaffirm that this anti-corrosion protection is fundamental in preserving the environment, that corrosion of the tanks will provide leaks and contamination in the groundwater. The use of gelatin in experiment of Figure 13 aims to highlight the reduction of the conductivity of the corrosive medium.

\section{Conclusions}

Based on the above it can be concluded that:

- Corrosion is a permanent challenge to mankind, because when science evolves, creating and applying technology and advances, more space and ways are found to do this;

- Cathodic protection can be considered as a successful environmental preservation technique when it is used in the external protection of pipelines, gas pipelines, water mains, and tanks buried underground or placed flat on the ground;

- It is important to emphasize the need for corrosion protection in fuel storage tanks due to the social responsibility to preserve the environment, especially with respect to groundwater contamination;

- Awareness of critical techniques, the size of projects involving tank farms or gas stations must be grounded in engineering courses aimed at training a conscious professional in anticorrosive techniques compatible with the environment. 


\section{REFERENCES}

[1] R. W. Revie, "Corrosion and corrosion control", John Wiley \& Sons, 2008.

[2] P. R. Roberge, “Handbook of Corrosion Ingeneering”. New York: McGraww-Hill, 2000.

[3] W. von Baeckmann, W. Schwenk and W. Prinz, "Handbook of Cathodic Corrosion Protection. Theory and Pratice of Electrochemical Protection Process", Houston, TX: (GPF) Gulf Professional Publishing, 1997.

[4] L. E Moschini, J.E. dos Santos and J. S. R. Pires, "Environmental diagnosis of risk áreas related to gas stations", Brazilian Archives of Biology and Technology, vol 48, no.4, pp.657-666, July, 2005.
[5] M. E. Parker and E. G. Peattie, "Pipeline Corrosion and Cathodic Protection", Houston, TX: (GPF) Gulf Professional Publishing, 1997.

[6] P. A. Schweitzer, "Fundamentals of Corrosion: Mechanisms, Causes, and Preventative Methods", New York: CRC Press, 2010.

[7] L. L. Sheir, R. A. Jarman, and G. T. Burstein, "Corrosion", Volume 2, third edition, Oxford: Butterworth-Heinemann, 2000.

[8] F. B. Mainier, L. P. Nunes, L. P. Gomes, A. C. M. Rocha, "A Non-polluting Option Using Cathodic Protection for Hydrostatic Testing of Petroleum Tanks with Seawater", American Journal of Materials Science 2014, 4(5): 190-193 DOI: $10.5923 /$ j.materials.20140405.02 